\title{
PersistênCia e LiXiviação de Ametryn e Trifloxysulfuron-Sodium em Solo Cultivado com Cana-de-AçÚCAR ${ }^{1}$
}

\author{
Persistence and Leaching of Ametryn and Trifloxysulfuron-Sodium on Sugar-Cane Soil
}

\author{
VIVIAN, R. ${ }^{2}$, QUEIROZ, M.E.L.R. ${ }^{3}$, JAKELAITIS, A. ${ }^{4}$, GUIMARÃES, A.A. ${ }^{5}$, REIS, M.R. ${ }^{6}$, \\ CARNEIRO, P.M. ${ }^{5}$ e SILVA, A.A. ${ }^{7}$
}

\begin{abstract}
RESUMO - Este trabalho teve o objetivo de avaliar o comportamento da mistura comercial ametryn + trifloxysulfuron-sodium em área cultivada com cana-de-açúcar, em relação ao seu potencial de lixiviação e persistência no ambiente. A área sobre Argissolo Vermelho-Amarelo eutrófico foi dividida em duas subáreas, nas quais foram cultivadas as variedades de cana SP 791011 e SP 801816. Os tratamentos foram compostos pelas aplicações em pré e pósemergência da mistura comercial dos herbicidas nos anos de 2003 e 2003/2004, sendo realizadas quatro amostragens de solo em duas profundidades $(0$ a $0,10 \mathrm{~m}$ e 0,10 a $0,20 \mathrm{~m})$. $\mathrm{Na}$ avaliação dos resíduos, utilizaram-se os métodos de bioensaio e cromatografia líquida de alta eficiência (CLAE). Ambos os métodos foram satisfatórios nas avaliações dos resíduos da mistura comercial, embora a utilização do bioensaio não tenha permitido a avaliação dos compostos separadamente. Pelos dados da análise simultânea de ametryn e trifloxysulfuronsodium por CLAE, verificou-se que a maioria dos resíduos de ametryn permaneceu na camada de 0 a 0,10 $\mathrm{m}$ de profundidade do solo, com persistência superior a 180 dias após a aplicação (DAA), em solo pulverizado, em 2003/2004. Resíduos de ametryn também foram constatados, na profundidade de 0,10 a 0,20 m do solo, para as aplicações realizadas em 2003/2004, enfatizando-se os riscos de lixiviação e contaminação de águas com esse herbicida. Nas aplicações realizadas somente em 2003 não se constatou efeito residual significativo aos 490 DAA. Diferenças residuais nas subáreas cultivadas com as variedades SP 791011 e SP 801816 foram atribuídas aos diferentes teores de argila e matéria orgânica do solo. Não foram detectados resíduos de trifloxysulfuron-sodium em nenhuma época de coleta do solo, sendo isso justificado pelo fato de o limite de quantificação por CLAE $\left(0,06 \mathrm{mg} \mathrm{L}^{-1}\right)$ estar acima da dose utilizada desse herbicida (37 $\left.\mathrm{g} \mathrm{ha}^{-1}\right)$.
\end{abstract}

Palavras-chave: herbicidas, sorção, resíduos, Saccharum spp.

\begin{abstract}
The aim of the work was to evaluate the behavior of the ametryn + trifloxysulfuronsodium commercial mixture in sugar-cane crop, as related to leaching potential and persistence in the environment. The Typic Haplufalf soil area was divided into two sub areas where the sugar-cane varieties SP 791011 and SP 801816 were cultivated. The treatments were constituted by pre and post-emergence applications of the commercial herbicide mixtures in 2003 and 2003 +2004 , with four soil samplings 0-0.10 and 0.10-0.20 m deep. Bioassay and High Performance Liquid Chromatography (HPLC) methods were used to evaluate the residues. Both methods were found satisfactory for evaluation of the commercial mixture residue, although the bioassay use did not allow evaluating the compounds separatedly. According to the data obtained from the simultaneous analysis of ametryn and trifloxysulfuron-sodium by HPLC, most of the ametryn residues remained in the soil layer $0-0.10 \mathrm{~m}$ deep, persisting for over 180 days after application $(D A A)$, in soil sprayed in $2003+2004$. Ametryn residues in $0.10-0.20 \mathrm{~m}$ deep, were as well found for the treatments sprayed in $2003+2004$ and showed the risks of leaching and
\end{abstract}

Recebido para publicação em 11.4.2006 e na forma revisada em 27.2.2007.

Doutorando em Fitotecnia, Escola Superior de Agricultura "Luiz de Queiroz" - ESALQ/USP, 13418-900 Piracicaba-SP, <agrovivian@yahoo.com.br>. ${ }^{3}$ Prof ${ }^{a}$. Adjunta, Departamento de Química da Universidade Federal de Viçosa - DEQ/UFV. ${ }^{4}$ Prof., Fundação Universidade Federal de Rondônia - UNIR; ${ }^{5}$ Bolsista de Iniciação Científica - UFV; ${ }^{6}$ Mestrando em Fitotecnia, DFT/UFV; ${ }^{7}$ Prof. Associado - DFT/UFV. 
contaminating water with this herbicide. For the treatments sprayed only in 2003, a significant residual effect was not detected 490 days after application. Differences in residual effect among cultivated sub areas with the variety SP 791011 and SP 801816 were due to the different amounts of clay and organic matter in the soil. Residues of trifloxysulfuron-sodium were not found in any period of the soil sampling, as the limit of quantification by HPLC $\left(0.06 \mathrm{mg} \mathrm{L}^{-1}\right)$ is higher than the used dose of this herbicide $\left(37 \mathrm{~g} \mathrm{ha}^{-1}\right)$.

Keywords: herbicides, sorption, residues, Saccharum spp.

\section{INTRODUÇÃO}

Ocupando área de 5,2 milhões de hectares, a cultura da cana-de-açúcar é um dos principais produtos agrícolas do Brasil, com potencial energético de produção equivalente a 820 mil barris/dia de petróleo, ou seja, 50\% do consumo total de derivados do petróleo no país (Carvalho, 2004). Entretanto, a utilização do controle químico é, atualmente, uma das ferramentas indispensáveis para essa cultura, principalmente por ser cultivada em larga escala, em que diversos herbicidas são aplicados anualmente (Southwick et al., 2002; Silva et al., 2005).

Assim, devido ao seu uso intensivo, os herbicidas são apontados como o grupo de pesticidas mais freqüentemente detectado em estudos de qualidade de águas superficiais e subterrâneas (Carter, 2000; Tanabe et al., 2001), sendo as áreas próximas ao cultivo de cana-de-açúcar de maior ocorrência de resíduos desses compostos (Southwick et al., 2002).

Dentre os principais processos relacionados ao uso incorreto e abusivo de herbicidas, a lixiviação e o escorrimento superficial no solo destacam-se pela sua contribuição na contaminação de águas (Tanabe et al., 2001). Além desses problemas, Skinner et al. (1997) ressaltam os efeitos econômicos indiretos proporcionados pelos custos posteriores de tratamento e descontaminação de mananciais hídricos.

Todavia, a movimentação das moléculas dos herbicidas e sua interação nos processos adsortivos e dessortivos ainda são pouco conhecidas nas condições de clima e solos brasileiros. Outros processos, assim como a sorção e dessorção, também influenciam o destino e movimento dos herbicidas no solo
(Ahmad et al., 2001), ocorrendo, geralmente, uma relação inversa entre a sorção e o potencial de lixiviação desses compostos (Lavorenti, 1999). Segundo Andréa \& Luchini (2002), a sorção de pesticidas no solo também é importante, principalmente por se relacionar diretamente com os processos de disponibilidade para a atividade do composto, ataque microbiano e biodegradação e inversamente com a possibilidade de lixiviação e contaminação de águas.

No entanto, o processo de distribuição e degradação de herbicidas no solo é dinâmico e único para cada relação solo-herbicida. Além disso, sua dependência está relacionada a propriedades físico-químicas dos compostos, sua interação com o solo e tempo de meia-vida $\left(t_{1 / 2}\right)$, condições climáticas, ve ge tação e cobertura, propriedades físicas, químicas e biológicas do solo e manejo da área (Walker, 1987; Clay, 1993; Carter, 2000; Kudsk \& Streibig, 2003; Hager \& Nordby, 2004). Dessa forma, estudos comumente conduzidos em laboratório, com objetivo de avaliar o potencial de lixiviação e contaminação de solo e água por herbicidas, nem sempre representam o comportamento real verificado em condições naturais in situ.

Dos herbicidas recentemente disponiveis para controle de plantas daninhas em canade-açúcar, a mistura comercial de ametryn + trifloxysulfuron-sodium apresenta amplo espectro de ação e ótima seletividade para essa cultura (Rodrigues \& Almeida, 2005). O ametryn, pertencente ao grupo das s-triazinas, atua na inibição do fotossistema II, encontrando-se registrado no Brasil para as culturas de algodão, citros, milho e cana-de-açúcar. Já o trifloxysulfuron-sodium, o qual faz parte do grupo químico das sulfoniluréias, foi recentemente desenvolvido para uso nas culturas de cana-de-açúcar e algodão, inibindo a enzima 
acetolactato sintase - ALS (Silva et al., 2005; Rodrigues \& Almeida, 2005).

Entre os estudos realizados com águas superficiais e subterrâneas, o ametryn foi detectado em seis estados dos Estados Unidos, em pouquíssimas amostras de água superficial e em 4\% das amostras de águas subterrâneas (Extoxnet - Extension Toxicology Network, 2005). Já segundo Pfeuffer \& Rand (2004), o monitoramento de pesticidas realizado entre 1992 e 2001 no sul da Flórida revelou que os herbicidas ametryn e atrazine foram os compostos mais comumente encontrados em águas superficiais. Recentemente, Mitchell et al. (2005) também identificaram resíduos de ametryn $\left(0,3 \mu \mathrm{g} \mathrm{L}^{-1}\right)$ e outros quatro herbicidas em águas de rios pertencentes à região de Mackay Whitsunday, na Austrália.

No Brasil, Laabs et al. (2002) estudaram a contaminação da região nordeste do Pantanal mato-grossense por pesticidas utilizados na agricultura. Foram detectados resíduos de ametryn na maioria das amostras coletadas em águas de superficie, embora em baixa concentração. Entretanto, em amostras de sedimentos, as concentrações foram superiores a 4,5 $\mu \mathrm{g} \mathrm{kg}^{-1}$. A elevada freqüência de detecção de ametryn, juntamente com sua alta concentração em algumas amostras, foi atribuída, conforme os autores, ao intenso cultivo de cana-de-açúcar no nordeste do pantanal.

Em relação ao trifloxysulfuron-sodium, os estudos desse herbicida em amostras de solo de clima tropical são ainda mais escassos, sendo urgentes e necessários estudos nessa linha de pesquisa para o país, sem as quais se torna difícil a manutenção da qualidade de vida e diversidade do meio ambiente.

Dessa forma, o objetivo do estudo foi avaliar a persistência e o potencial de lixiviação de ametryn + trifloxysulfuron-sodium no solo, além de contribuir na previsão do comportamento desses herbicidas quando aplicados em área cultivada com cana-de-açúcar.

\section{MATERIAL E MÉTODOS}

\section{Descrição da instalação e manejo do experimento}

As avaliações de resíduos dos herbicidas trifloxysulfuron-sodium e ametryn foram realizadas no Centro Experimental de Pesquisa Cana-de-Açúcar - CECA $\left(20^{\circ} 20^{\prime} \mathrm{S}\right.$ e $\left.43^{\circ} 48^{\prime} \mathrm{W}\right)$, da Universidade Federal de Viçosa, em Ponte Nova-MG. A área, sobre Argissolo VermelhoAmarelo eutrófico - PVAe (Tabela 1), foi dividida em duas subáreas dispostas paralelamente, nas quais foram plantados os cultivares SP 801816 e SP 791011 de cana-de-açúcar, em fevereiro de 2003. Cada subárea compôs um experimento em esquema fatorial $(2 \mathrm{x} 4$ profundidades e épocas de coleta do solo), com delineamento em blocos e três repetições, os quais receberam os cinco tratamentos apresentados na Tabela 2. Os fatores avaliados em relação aos resíduos dos herbicidas foram os próprios tratamentos e as profundidades de coleta do solo $(0-0,10$ e 0,10 $0,20 \mathrm{~m}$ ), em quatro períodos, cujos niveis foram avaliados pelos testes de Tukey e F, de acordo com a significância da interação, a $5 \%$ de probabilidade. As unidades experimentais foram compostas por parcelas medindo 5,6 x 5,0 m e área útil de $11,2 \mathrm{~m}^{-2}$, utilizando-se $1,4 \mathrm{~m}$ entre as linhas de plantio. As pulverizações da mistura comercial ametryn + trifloxysulfuron-sodium foram feitas em pré ou pós-emergência, na dose de $2,0 \mathrm{~kg} \mathrm{ha}^{-1}$, aplicando-se o equivalente a $200 \mathrm{~L} \mathrm{ha}^{-1}$ de calda. A adubação utilizada foi de $500 \mathrm{~kg}$ da formulação NPK 8-28-16, juntamente com o plantio, com adubação suplementar em cobertura, em 2004. As condições climáticas do local foram monitoradas, sendo as médias referentes ao periodo experimental apresentadas na Figura 1.

\section{Amostragem e preparo do solo}

O solo foi coletado nas profundidades de 0 a 0,10 e 0,10 a 0,20 m, em cada época amostral, totalizando quatro coletas, correspondentes aos intervalos de 490 a 670 e 467 a 647 dias após a aplicação dos herbicidas (DAA) em pré e pós-emergência, respectivamente, em 2003. Em 2004, o intervalo de coleta e avaliação dos resíduos foi de 18 a 198 e 45 a 165 DAA em pré e pós-emergência, respectivamente (Tabela 2). A primeira coleta, em 10.8.2004, foi realizada antes da aplicação dos herbicidas em pós-emergência do segundo ano.

As amostras de solo foram retiradas da área útil de cada parcela com cavadeira manual articulada. Inicialmente, removeu-se o material 
grosseiro da superficie, sendo então coletados os $0,10 \mathrm{~m}$ superiores do solo, em diâmetro aproximado de $50 \mathrm{~cm}$, para evitar a contaminação cruzada com as amostras de 0,10 a $0,20 \mathrm{~m}$, as quais foram coletadas em $25 \mathrm{~cm}$ de diâmetro. Após a coleta, o solo foi peneirado em malha de $2 \mathrm{~mm}$, seco ao ar e à sombra e, posteriormente, armazenado em sacos plásticos esterilizados, em freezer sob temperatura de $-18{ }^{\circ} \mathrm{C}$, para realização das análises. Foram coletadas duas subamostras por unidade experimental, misturadas e homogeneizadas, armazenando-se, aproximadamente, $2 \mathrm{~L}$ de solo para composição de amostra única.

Tabela 1 - Principais características físicas e químicas dos solos cultivados com cana-de-açúcar e utilizados na avaliação dos resíduos de ametryn e trifloxysulfuron-sodium

\begin{tabular}{|c|c|c|c|c|c|c|}
\hline \multirow{3}{*}{ Característica avaliada } & \multirow{3}{*}{\multicolumn{2}{|c|}{ Unidade }} & \multicolumn{4}{|c|}{ Solo $^{1 /}$} \\
\hline & & & \multicolumn{2}{|c|}{ PVAe - CV 791011} & \multicolumn{2}{|c|}{ PVAe - CV 801816} \\
\hline & & & $0-0,10 \mathrm{~m}$ & $0,10-0,20 \mathrm{~m}$ & $0-0,10 \mathrm{~m}$ & $0,10-0,20 \mathrm{~m}$ \\
\hline $\mathrm{pH}^{2 /}$ & \multirow{4}{*}{\multicolumn{2}{|c|}{$\mathrm{cmol}_{\mathrm{c}} \mathrm{dm}^{-3}$}} & 6,60 & 6,50 & 6,60 & 6,80 \\
\hline $\mathrm{H}^{+}+\mathrm{Al}^{+3}$ & & & 1,65 & 1,65 & 1,32 & 1,32 \\
\hline $\mathrm{SB}^{3 /}$ & & & 4,26 & 3,84 & 3,19 & 3,05 \\
\hline $\mathrm{CTC}^{4 /}$ & & & 5,91 & 5,49 & 4,51 & 4,37 \\
\hline $\mathrm{V}$ & \multirow{2}{*}{\multicolumn{2}{|c|}{$\%$}} & 72 & 70 & 71 & 70 \\
\hline MO & & & 1,58 & 1,45 & 1,19 & 0,79 \\
\hline \multirow{3}{*}{ Fração Mineral } & Areia & \multirow{3}{*}{$\%$} & 43 & 41 & 58 & 61 \\
\hline & Silte & & 18 & 19 & 13 & 11 \\
\hline & Argila & & 39 & 40 & 29 & 28 \\
\hline Text. ${ }^{-5}$ & \multirow{2}{*}{\multicolumn{2}{|c|}{$\%$}} & $\mathrm{~A}$ & A & FAA & FAA \\
\hline $\mathrm{ADA}^{6 /}$ & & & 28 & 30 & 24 & 22 \\
\hline $\mathrm{EU}^{7}$ & \multicolumn{2}{|c|}{$\mathrm{kg} \mathrm{kg}^{-1}$} & 0,291 & 0,295 & 0,225 & 0,234 \\
\hline
\end{tabular}

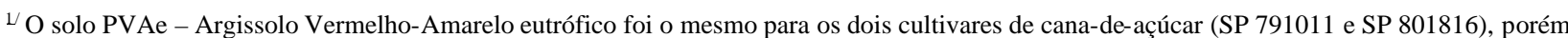
as análises foram estratificadas, devido à sua heterogeneidade local; ${ }^{21} \mathrm{pH}$ em água: relação 1:2,5; ${ }^{31} \mathrm{Ca}, \mathrm{Mg}$ e Al: extrator $\mathrm{KCl} 1 \mathrm{~mol} \mathrm{\textrm {L } ^ { - 1 }}$, K: extrator Mehlich I, H + Al: extrator Acetato de cálcio 0,5 mol/L, a pH 7,0; ${ }^{4}$ Capacidade de troca de cátions estimada ao $\mathrm{pH} 7,0 ;{ }^{5 /}$ Textura: A argila; FAA - franco-argilo-arenosa; ${ }^{6 /} \mathrm{ADA}$ : argila dispersa em água; ${ }^{7 /} \mathrm{EU}$ : equivalente de umidade do solo.

Tabela 2 - Tratamentos utilizados no cultivo de cana-de-açúcar (cv. SP 801816 e SP 791011) para avaliação dos resíduos de ametryn e trifloxysulfuron-sodium, nas profundidades de 0-10 e 0,10-0,20 m. Viçosa-MG, 2005

\begin{tabular}{|c|c|c|c|c|c|}
\hline \multirow{2}{*}{ Tratamento } & \multicolumn{2}{|c|}{ Aplicação $1^{\circ}$ ano $(2003)^{*}$} & \multicolumn{2}{|c|}{ Aplicação $2^{\circ}$ ano (2004)* } & \multirow{2}{*}{$\mathrm{DAA}^{\underline{2} !}$} \\
\hline & Pré-emergência & Pós-emergência & Pré-emergência & Pós-emergência & \\
\hline 1 & $\begin{array}{c}\text { ametryn }+ \\
\text { trifloxysulfuron- } \\
\text { sodium }{ }^{1 /}\end{array}$ & - & - & - & $490-670(2003)$ \\
\hline 2 & - & $\begin{array}{c}\text { ametryn + } \\
\text { trifloxysulfuron- } \\
\text { sodium }\end{array}$ & - & - & $467-647(2003)$ \\
\hline 3 & $\begin{array}{l}\text { ametryn + } \\
\text { trifloxysulfuron- } \\
\text { sodium }\end{array}$ & - & $\begin{array}{l}\text { ametryn + } \\
\text { trifloxysulfuron- } \\
\text { sodium }\end{array}$ & - & $\begin{array}{c}490-670(2003) \\
e \\
18-198(2004)\end{array}$ \\
\hline 4 & - & $\begin{array}{l}\text { ametryn + } \\
\text { triflox ysulfuron- } \\
\text { sodium }\end{array}$ & - & $\begin{array}{l}\text { ametryn }+ \\
\text { trifloxysulfuron- } \\
\text { sodium }\end{array}$ & $\begin{array}{c}467-647(2003) \\
\mathrm{e} \\
45-165(2004)\end{array}$ \\
\hline 5 & \multicolumn{5}{|c|}{ Testemunha sem herbicida } \\
\hline
\end{tabular}

* Volume de calda utilizado: $200 \mathrm{~L} \mathrm{ha}^{-1}$; 1 Mistura comercial Krismat ${ }^{\circledR}$, contendo 1,463 kg de ametryn + 37 g de trifloxysulfuron-sodium;

${ }^{2}$ 'DAA - intervalo de coletas do solo em dias após a aplicação dos herbicidas (pré ou pós-emergência), referentes à aplicação no $1^{\circ}$ e/ou $2^{0}$ ano. As coletas ocorreram em 10/8/2004, 10/10/2004, 10/11/2004 e 10/2/2005. 


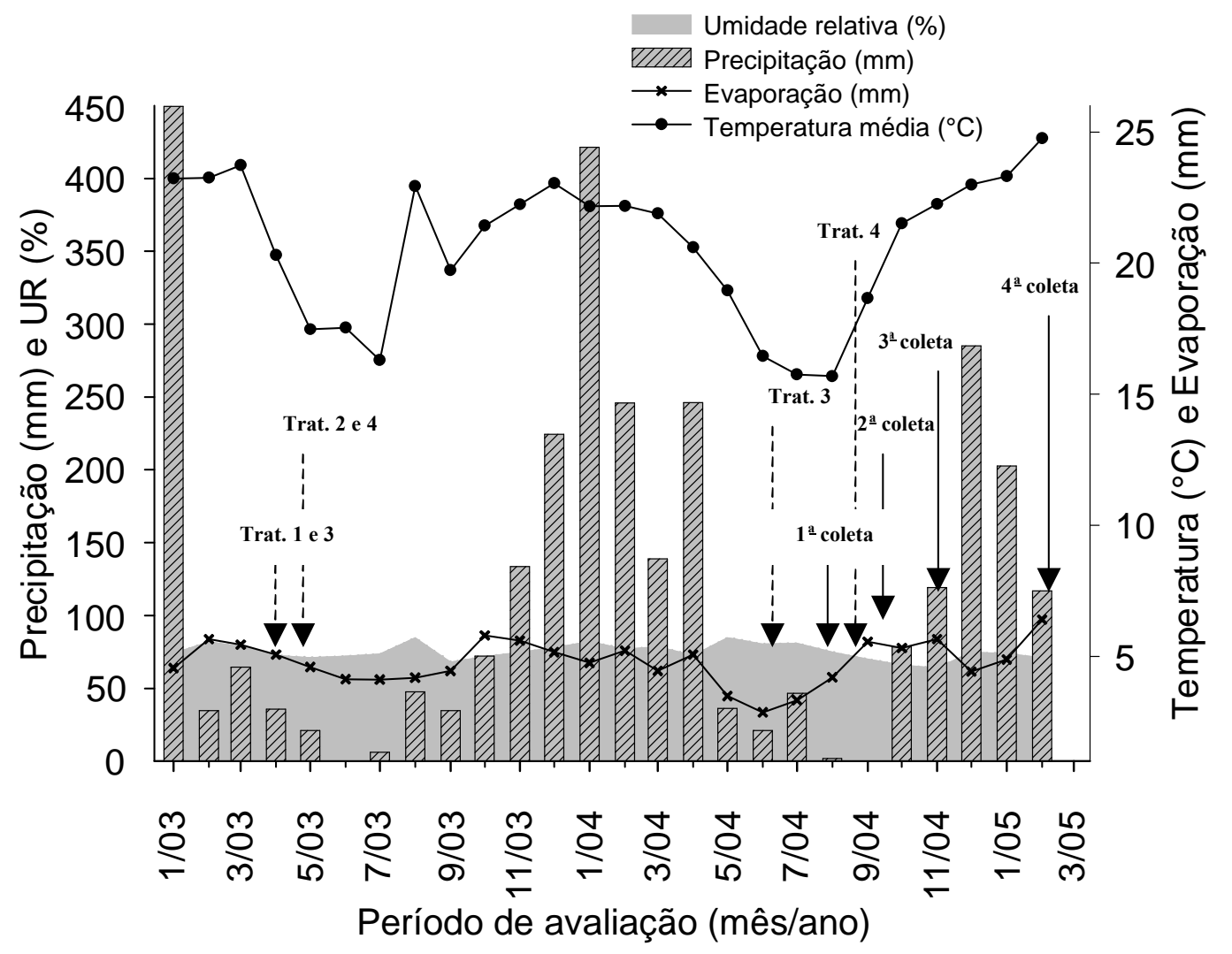

Figura 1 - Médias mensais para umidade relativa (\%), precipitação pluvial (mm), evaporação (mm) e temperatura média do ar $\left({ }^{\circ} \mathrm{C}\right)$ observadas na estação experimental de Ponte Nova-MG $\left(20^{\circ} 20^{\prime}\right.$ 'S e $\left.43^{\circ} 48^{\prime} \mathrm{W}\right)$ durante a condução do experimento. Os tratamentos 1, 2 e 3, 4 referem-se, respectivamente, às aplicações em pré e pós-emergência, em 2003 e 2003/2004.

\section{Avaliação dos resíduos por bioensaio}

Utilizou-se o bioensaio como método indireto de quantificação dos resíduos de ametryn e trifloxysulfuron-sodium no solo. Para isso, em ensaio preliminar, selecionou-se espécie bioindicadora para o herbicida, adotando-se o pepino (Cucumis sativus) como espécie adequada. Posteriormente, utilizando-se dois substratos - areia lavada e o solo em estudo (PVAe), isentos de herbicidas -, foram determinadas em casa de vegetação as curvas de dose-resposta para os herbicidas. Soluções com as doses crescentes da mistura ametryn + trifloxysulfuron-sodium $(0 ; 1,17 ; 2,34 ; 4,70$; 9,$38 ; 18,75 ; 37,5 ; 75,0 ; 150,0$ e $300,0 \mathrm{~g} \mathrm{ha}^{1}$ ) foram aplicadas em pré-emergência sobre vasos contendo $120 \mathrm{~g}$ dos substratos, após a semeadura de quatro sementes de pepino por vaso. O solo foi mantido próximo à capacidade de campo. Foram utilizadas cinco repetições para cada dose testada. Após completa emergência, fez-se o desbaste, permanecendo duas plantas uniformes por vaso.

Aos 21 dias após a semeadura, avaliaramse a fitotoxicidade (escala visual variando de 0 a 100 , em que 0 significa sem fitotoxicidade e 100 representa a morte da planta indicadora EWRC, 1964), a altura e a biomassa seca da parte aérea da planta indicadora. Para interpretação dos resultados, os valores de biomassa seca da parte aérea foram comparados aos do tratamento sem herbicida (dose zero), sendo submetidos à análise estatística, utilizandose o modelo log-logístico não-linear $\hat{Y}=b+$ $\left\{\mathrm{a}-\mathrm{b} /\left(1+\left(x / \mathrm{I}_{50}\right)^{\mathrm{c}}\right\}\right.$ (Seefeldt et al., 1995; Stork \& Hannah, 1995), em que $a$ e $b$ correspondem ao nível máximo e mínimo da curva de doseresposta; $c$, ao declive da curva em torno do $\mathrm{I}_{50}$; e o $\mathrm{I}_{50}$, à dose-resposta referente à redução de $50 \%$ da massa seca da parte área da planta indicadora. Os valores obtidos de $\mathrm{I}_{50}$ em solo e areia foram utilizados para cálculo da relação 
adsortiva do herbicida no solo, expresso pela fó rmula $\mathrm{RA}=\left[\left(I_{50}\right.\right.$ solo $-I_{50}$ areia $\left.)\right]$ $I_{50}$ areia $]^{*} 100$. Essa relação percentual foi utilizada para correção dos cálculos de resíduos de ametryn + trifloxysulfuron-sodium no solo. Para isso, os valores obtidos de biomassa seca da parte aérea da planta indicadora, em cada coleta de solo, foram comparados aos obtidos para a curva de dose-resposta em solo PVAe e, aos valores residuais encontrados, acrescentou-se o percentual da RA calculada anteriormente.

Posteriormente, o solo PVAe já amostrado e previamente tratado foi submetido ao mesmo procedimento de avaliação utilizado na confecção da curva de dose-resposta, entretanto sem a aplicação do herbicida. Para cada amostra coletada em campo, foram utilizadas quatro repetições de $120 \mathrm{~g}$ de solo cada, nos quais se semeou a espécie indicadora, cultivada em casa de vegetação. Os valores obtidos de fitotoxicidade, altura e biomassa seca da parte aérea das plantas foram comparados aos do solo coletado na parcela testemunha (sem aplicação do herbicida); posteriormente, para quantificação dos resíduos desse no solo, utilizou-se a curva de dose-resposta da biomassa seca da espécie indicadora, previamente determinada (Figura 2). Os resultados da atividade residual dos herbicidas foram submetidos à ANOVA, sendo, quando significativos, realizadas comparações de médias pelo teste de Tukey a $5 \%$ de probabilidade.

\section{Análise dos resíduos por CLAE}

A metodologia inicialmente testada foi baseada na extração líquido-líquido dos herbicidas com solução extratora composta por metanol:água:ácido fosfórico 45:50:0,5 (v:v:v), proposta por Vega (2000), para extração de triflusulfuron-metil em amostras de água e solo. Variações no tempo, pH e composição da solução de extração foram realizadas na otimização do método, com objetivo de aumentar o percentual de recuperação. Entretanto, a técnica proposta por Pereira (2005), com extração líquido-líquido e partição em baixa temperatura, foi a que apresentou os melhores

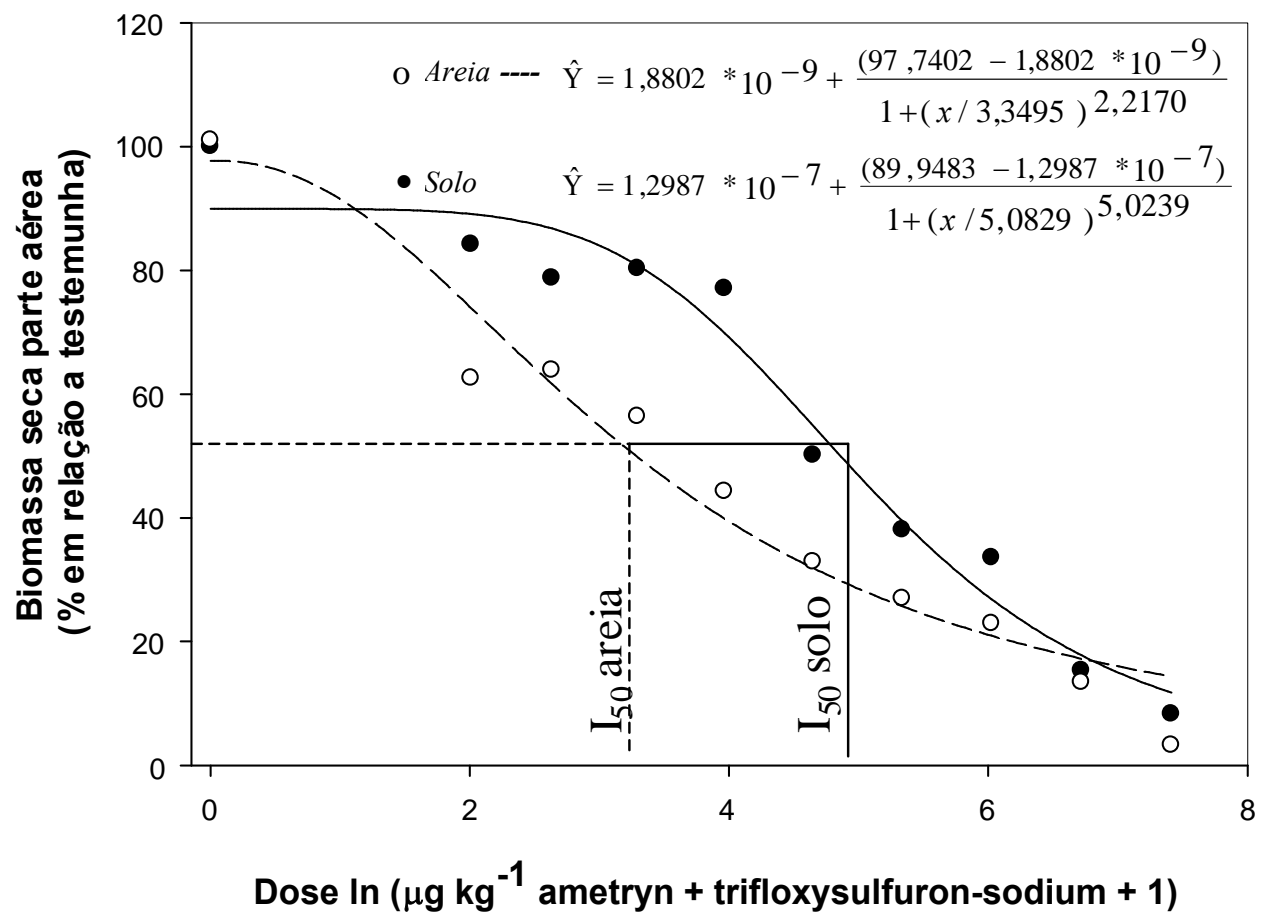

Figura 2 - Estimativas das curvas de dose-resposta para biomassa seca da parte aérea de Cucumis sativus, avaliada aos 21 dias após aplicação dos herbicidas, em função de doses $(x)$ crescentes da mistura comercial ametryn + trifloxysulfuron-sodium aplicadas em Argissolo Vermelho-Amarelo eutrófico (-) e em areia (- - -). 
resultados para a extração simultânea de ametryn e trifloxysulfuron-sodium em solo. Os parâmetros da validação, juntamente com algumas características dos herbicidas, encontram-se na Tabela 3. Pela metodologia previamente validada e otimizada, utilizaramse $10,0 \mathrm{~mL}$ da solução extratora 65:20:15 (v:v:v) de acetonitrila, água e acetato de etila, respectivamente, em 2,0 g de solo peneirado em malha de $2 \mathrm{~mm}$ e seco ao ar, com agitação posterior durante 60 minutos, em mesa horizontal. Após esse procedimento, os erlenmeyers devidamente vedados, contendo solo + solução extratora, permaneceram em freezer durante 12 horas a $-18^{\circ} \mathrm{C}$, para separação das fases com diferentes polaridades. Posteriormente, a solução sobrenadante que não sofreu congelamento foi coletada em balão volumétrico de $10,0 \mathrm{~mL}$, para afe rição do volume. Buscou-se recuperar o máximo dos $10,0 \mathrm{~mL}$ iniciais adicionados da solução extratora, fazendo-se três lavagens sucessivas

Tabela 3 - Principais propriedades dos herbicidas ametryn e trifloxysulfuron-sodium, juntamente com os parâmetros obtidos na validação do método de extração simultânea em solo, por partição em baixa temperatura

\begin{tabular}{|c|c|c|}
\hline \multicolumn{3}{|c|}{ Principais Propriedades dos Compostos Avaliados } \\
\hline \multirow[b]{2}{*}{ Propriedade } & \multicolumn{2}{|c|}{ Herbicida ${ }^{\underline{\prime}}$} \\
\hline & Ametryn & $\begin{array}{c}\text { Trifloxysulfuron- } \\
\text { sodium }\end{array}$ \\
\hline Peso molecular & 227,35 & 459,34 \\
\hline $\mathrm{pka}^{2}$ & 4,1 & 4,76 \\
\hline $\log k_{\text {ow }}$ & 2,63 & 1,40 \\
\hline Solubilidade em água $\left(\mathrm{mg} \mathrm{L}^{-1}\right)$ & $200\left(22{ }^{\circ} \mathrm{C}\right)$ & $352\left(25^{\circ} \mathrm{C}\right)$ \\
\hline \multicolumn{3}{|c|}{ Validação do Método de Extração } \\
\hline Parâmetros avaliados & Ametryn & $\begin{array}{l}\text { Trifloxysulfuron- } \\
\text { sodium }\end{array}$ \\
\hline Limite de detecção $\left(\mathrm{mg} \mathrm{L}^{-1}\right)$ & 0,01 & 0,02 \\
\hline Limite de quantificação $\left(\mathrm{mg} \mathrm{L}^{-1}\right)$ & 0,04 & 0,06 \\
\hline Percentual de recuperação ${ }^{3 /}$ & 83,31 & 94,72 \\
\hline Coeficiente de variação $(\%)^{\underline{4}}$ & 8,44 & 1,40 \\
\hline Curva analítica ${ }^{\underline{5}}$ & $\begin{array}{c}\hat{Y}=116972 \mathrm{x} \\
+8215,80\end{array}$ & $\begin{array}{c}\hat{Y}=43066 \mathrm{x}+ \\
2066,30\end{array}$ \\
\hline Coeficiente de determinação $\left(\mathrm{r}^{2}\right)$ & 0,9999 & 0,9994 \\
\hline
\end{tabular}

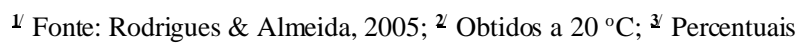
médios obtidos entre as médias dos níveis de fortificação, correspondentes a 1, 3 e 10 vezes o Limite de Quantificação (LQ). As médias dentro de cada nível de fortificação foram calculadas a partir de sete repetições; ${ }^{4 /}$ Coeficientes de variação médios obtidos a partir das médias de cada nível de fortificação (1, 3 e 10 vezes o LQ); ${ }^{\mathbb{5}}$ Curvas utilizadas nos cálculos de resíduos no solo, em que $X$ representa a concentração do composto em $\mu \mathrm{g} \mathrm{mL} \mathrm{m}^{-1}$. com acetonitrila e posterior readição no balão volumétrico. Após atingir a temperatura ambiente, os balões foram completados para $10,0 \mathrm{~mL}$ e parte da solução foi filtrada em filtro Millipore com membrana PTFE 0,45 $\mu \mathrm{m}$, para posterior análise cromatográfica. Todos os reagentes utilizados foram grau espectrofotométrico de uso em cromatógrafo líquido.

Para análise cromatográfica, utilizou-se cromatógrafo líquido de alta eficiência (CLAE) marca Shimadzu SPD 2A com detector UV, equipado com coluna Lichrosorb RP-18, 250 $\mathrm{x} 4 \mathrm{~mm}$ e $5 \mu \mathrm{m}$ de espessura de poro. O volume de injeção foi de $20 \mu \mathrm{L}$ e a fase móvel composta por acetonitrila e água, na respectiva proporção de 48:52 (v:v) e 1\% de ácido fosfórico concentrado. Para determinação dos resíduos em cada amostra, compararam-se as áreas obtidas nos cromatogramas em cada ensaio com as áreas dos cromatogramas das curvas analíticas de cada herbicida, com a plotagem da área do cromatograma do padrão analítico vs concentração. Todas as análises foram realizadas em duplicata.

\section{RESULTADOS E DISCUSSÃO}

A partir das análises realizadas em solo PVAe (Tabela 1), verifica-se variabilidade principalmente na CTC e no teor de MO. Além disso, observa-se que na subárea onde foi cultivada a variedade SP 791011 os teores de argila foram maiores que aqueles apresentados na subárea de cultivo da SP 801816, sendo suficiente para que a classificação textural fosse alterada de argila para franco-argiloarenosa, respectivamente. Devido ao processo dinâmico de interação de herbicidas no solo, Liu et al. (2002) avaliaram a influência da variabilidade do solo e a formação do relevo no comportamento de atrazine. Esses autores concluiram que principalmente o relevo tem ação importantíssima na mineralização e dissipação do herbicida, devendo ser levado em consideração nos estudos de persistência e lixiviação desses compostos. Assim, a caracterização e análise distinta entre as subáreas foi favorável para posterior interpretação dos dados obtidos.

Nas avaliações dos resíduos por bioensaio, as curvas de dose-resposta em solo (PVAe) e areia apresentaram parâmetros distintos, com 
redução brusca da biomassa seca de $C$. sativus cultivada em areia em relação ao seu cultivo no solo, em função da dose da mistura dos herbicidas (Figura 2). A diferença pode ser confirmada pelos valores de $\mathrm{I}_{50}$ de 3,3495, obtido em areia, e de 5,0829, obtido em solo. A RA calculada entre os $\mathrm{I}_{50}$ foi de $51,75 \%$, o que significa que mais de $50 \%$ da mistura comercial ametryn + trifloxysulfuron-sodium adicionada foi adsorvida pelo solo PVAe, sendo esse percentual considerado nos cálculos de resíduos por bioensaio.

Pela altura das plantas indicadoras, avaliadas em cada coleta de solo cultivado com a var. SP 801816 (Tabela 4), verifica-se que os maiores $(\mathrm{P}<0,05)$ valores foram constatados naquelas crescidas em solo isento de herbicida (tratamento 5), com exceção da última coleta, em 10/2/2005. Observam-se reduções $(\mathrm{P}<0,05)$ na altura das plantas, principalmente para os tratamentos 3 e 4, nas coletas 1 e 2 , respectivamente, em 0 a $0,10 \mathrm{~m}$ de profundidade do solo. Nas coletas realizadas entre 0,10 e $0,20 \mathrm{~m}$, pouca diferença $(\mathrm{P}<0,05)$ pode ser observada entre os tratamentos, exceto para os tratamentos 3 (primeira coleta) e 4 (segunda coleta), devido principalmente à aplicação recente (2004) de ametryn + trifloxysulfuronsodium. Verifica-se ainda que, na última coleta do solo, a altura das plantas em cada tratamento foi semelhante $(P>0,05)$, não sendo mais constatada a ação de ametryn e trifloxysulfuron-sodium sobre a espécie indicadora. Para as avaliações de biomassa seca de C. sativus, semeada no solo cultivado com var. SP 801816 (Tabela 5), observam-se diferenças $(\mathrm{P}<0,05)$, principalmente, para os tratamentos 3 e 4, os quais receberam a mistura ametryn + trifloxysulfur on-sodium em 2003 e 2004, apresentando as maiores reduções de biomassa seca nos períodos iniciais de amostragem do solo. Já para a última coleta, em 10.2.2005, os percentuais de massa seca em relação à testemunha não diferiram entre tratamentos e profundidades de coleta do solo, indicando a ausência de resíduos dos herbicidas.

$\mathrm{Na}$ subárea cultivada com a var. SP 791011 , verifica-se, novamente, efeito $(\mathrm{P}<0,05)$ do herbicida sobre altura (Tabela 6) e biomassa seca (Tabela 7) da planta indicadora, para os tratamentos 3 e 4, com diferenças constatadas na primeira e segunda coletas, logo após a aplicação dos herbicidas em 2004. Nos tratamentos que receberam o herbicida somente em

Tabela 4 - Estimativas das médias das alturas (cm) das plantas indicadoras de Cucumis sativus em Argissolo VermelhoAmarelo eutrófico cultivado com cana-de-açúcar (SP 801816), coletado nas profundidades de 0 a 0,10 e 0,10 a $0,20 \mathrm{~m}$, em diferentes períodos, após a aplicação da mistura comercial dos herbicidas ametryn e triflox ysulfuron-sodium

\begin{tabular}{|c|c|c|c|c|c|}
\hline \multirow{3}{*}{ Profundidade (m) } & \multicolumn{5}{|c|}{ Altura $(\mathrm{cm})$} \\
\hline & \multicolumn{5}{|c|}{ Tratamento $^{1 /}$} \\
\hline & 1 & 2 & 3 & 4 & 5 \\
\hline & \multicolumn{5}{|c|}{$1^{\text {a }}$ Coleta $^{2 !}$} \\
\hline $0-0,10$ & $6,00 \mathrm{aBC}$ & $7,61 \mathrm{aAB}$ & $3,06 \mathrm{aC}$ & $5,88 \mathrm{aB}$ & $9,86 \mathrm{aA}$ \\
\hline \multirow[t]{2}{*}{$0,10-0,20$} & $5,47 \mathrm{aA}$ & $6,01 \mathrm{aA}$ & $3,58 \mathrm{aA}$ & $4,33 \mathrm{aA}$ & $5,86 \mathrm{bA}$ \\
\hline & \multicolumn{5}{|c|}{$2^{\mathrm{a}}$ Coleta } \\
\hline $0-0,10$ & $11,96 \mathrm{aAB}$ & $13,45 \mathrm{aA}$ & $7,21 \mathrm{bB}$ & $6,81 \mathrm{aB}$ & $15,62 \mathrm{aA}$ \\
\hline \multirow[t]{2}{*}{$0,10-0,20$} & $13,08 \mathrm{aAB}$ & $14,08 \mathrm{aA}$ & $12,08 \mathrm{aAB}$ & $8,29 \mathrm{aB}$ & $13,45 \mathrm{aAB}$ \\
\hline & \multicolumn{5}{|c|}{$3^{\text {a }}$ Coleta } \\
\hline $0-0,10$ & $8,79 \mathrm{aAB}$ & $6,29 \mathrm{aAB}$ & $4,92 \mathrm{aB}$ & $7,17 \mathrm{aAB}$ & $10,67 \mathrm{aA}$ \\
\hline \multirow[t]{2}{*}{$0,10-0,20$} & $6,31 \mathrm{bA}$ & $4,79 \mathrm{bA}$ & $4,08 \mathrm{aA}$ & $4,71 \mathrm{bA}$ & $6,92 \mathrm{bA}$ \\
\hline & \multicolumn{5}{|c|}{$4^{\mathrm{a}}$ Coleta } \\
\hline $0-0,10$ & $5,54 \mathrm{aA}$ & $6,17 \mathrm{aA}$ & $6,46 \mathrm{aA}$ & $6,05 \mathrm{aA}$ & $5,71 \mathrm{aA}$ \\
\hline $0,10-0,20$ & $5,62 \mathrm{aA}$ & $5,62 \mathrm{aA}$ & $5,54 \mathrm{aA}$ & $5,33 \mathrm{aA}$ & $4,53 \mathrm{aA}$ \\
\hline
\end{tabular}

Médias seguidas pela mesma letra minúscula (coluna) ou maiúscula (linha) não diferem entre si, pelos testes $\mathrm{F}$ e de Tukey (P>0,05), respectivamente, para cada coleta; $\stackrel{1 /}{-}$ Os tratamentos 1,2 e 3,4 referem-se, respectivamente, às aplicações em pré e pós-emergência em 2003 e 2003/2004, além do tratamento 5 (testemunha) sem herbicida; $\underline{2}$ As $1^{\mathrm{a}}, 2^{\mathrm{a}}, 3^{\mathrm{a}} \mathrm{e} 4^{\mathrm{a}}$ coletas referem-se, respectivamente, às datas de $10 / 8,10 / 10$, 10/11/2004 e 10/2/2005 de amostragem do solo. 
Tabela 5 - Estimativas das médias de biomassa seca $(\%$ em relação à testemunha) das plantas indicadoras de Cucumis sativus em Argissolo Vermelho-Amarelo eutrófico cultivado com cana-de-açúcar (SP 801816), coletado nas profundidades de 0 a 0,10 e 0,10 a $0,20 \mathrm{~m}$, em diferentes períodos, após a aplicação da mistura comercial dos herbicidas ametryn e trifloxysulfuron-sodium

\begin{tabular}{|c|c|c|c|c|}
\hline \multirow{2}{*}{$\begin{array}{c}\text { Profundidade } \\
(\mathrm{m})\end{array}$} & \multicolumn{5}{|c|}{ Biomassa Seca (\%) $^{-4} 1^{\mathrm{a}}$ Coleta $^{2}$} \\
\cline { 2 - 5 } & 1 & \multicolumn{5}{|c|}{2} & 4 \\
\hline & \multicolumn{5}{|c|}{ Tratamento $^{\underline{\underline{1}}}$} \\
\hline $0-0,10$ & $71,76 \mathrm{aA}$ & $83,70 \mathrm{bA}$ & $47,97 \mathrm{bB}$ & $75,58 \mathrm{aA}$ \\
\hline $0,10-0,20$ & $84,49 \mathrm{aB}$ & $116,73 \mathrm{aA}$ & $71,80 \mathrm{aB}$ & $90,46 \mathrm{aAB}$ \\
\hline & \multicolumn{5}{|c|}{$2^{\mathrm{a}}$ Coleta } \\
\hline $0-0,10$ & $87,20 \mathrm{aA}$ & $88,72 \mathrm{aA}$ & $56,58 \mathrm{bB}$ & $58,17 \mathrm{aB}$ \\
\hline $0,10-0,20$ & $94,39 \mathrm{aA}$ & $90,33 \mathrm{aA}$ & $87,41 \mathrm{aAB}$ & $73,91 \mathrm{aB}$ \\
\hline & \multicolumn{5}{|c|}{$3^{\mathrm{a}}$ Coleta } \\
\hline $0-0,10$ & $94,94 \mathrm{aA}$ & $97,27 \mathrm{aA}$ & $63,88 \mathrm{aB}$ & $70,13 \mathrm{aAB}$ \\
\hline $0,10-0,20$ & $91,02 \mathrm{aA}$ & $90,58 \mathrm{aA}$ & $82,75 \mathrm{aA}$ & $81,32 \mathrm{aA}$ \\
\hline & \multicolumn{5}{|c|}{$4^{\mathrm{a}}$ Coleta } \\
\hline $0-0,10$ & $94,76 \mathrm{aA}$ & $98,44 \mathrm{aA}$ & $98,98 \mathrm{aA}$ & $96,59 \mathrm{aA}$ \\
\hline $0,10-0,20$ & $114,77 \mathrm{aA}$ & $105,08 \mathrm{aA}$ & $114,19 \mathrm{aA}$ & $96,49 \mathrm{aA}$ \\
\hline
\end{tabular}

Médias seguidas pela mesma letra minúscula (coluna) ou maiús cula (linha) não diferem entre si pelos testes $\mathrm{F}$ e Tukey $(\mathrm{P}>0,05)$, respectivamente, para cad a coleta. ${ }^{\underline{1}}$ Os tratamentos 1,2 e 3,4 referem-se, respectivamente, às aplicações em pré e pós-emergência em 2003 e 2003/2004. O tratamento 5 - testemunha (não apresentado) foi considerado como $100 \%$ de biomassa seca. ${ }^{21}$ As $1^{\underline{a}}, 2^{\underline{a}}, 3^{\underline{a}}$ e $4^{\underline{a}}$ coleta, referem-se, respectivamente, às datas $10 / 8$, $10 / 10,10 / 11 / 2004$ e 10/2/2005 de amostragem do solo.
2003 (tratamentos 1 e 2) não se constatou efeito $(\mathrm{P}>0,05)$ de ametryn + trifloxysulfuronsodium sobre as plantas indicadoras. Além do efeito dos herbicidas, a oscilação constatada para a altura e biomassa seca entre a primeira e a última coleta do solo é decorrente, principalmente, das variações de temperatura e radiação ocorridas em cada período de cultivo, compreendido entre a semeadura e a avaliação, aos 21 dias, das plantas indicadoras em casa de vegetação.

Observando as avaliações realizadas para o solo cultivado com a var. SP 801816, verificam-se maiores diferenças em relação ao constatado para o solo cultivado com a var. SP 791011, tanto em altura como em biomassa seca das plantas indicadoras dos tratamentos 3 e 4, em relação à testemunha. Os maiores valores constatados para altura e biomassa seca, juntamente com os menores percentuais de fitotoxicidade de C. sativus (Figura 3a) semeada em solo cultivado com a var. SP 79 1011 em relação a SP 801816 (Figura 3b), podem estar relacionados, principalmente, às variações de textura e MO do solo. Sabe-se que a argila, juntamente com a MO, são constituintes do solo responsáveis pela maior sorção

Tabela 6 - Estimativas das médias das alturas $(\mathrm{cm})$ das plantas indicadoras de Cucumis sativus em Argissolo VermelhoAmarelo eutrófico cultivado com cana-de-açúcar (SP 791011), coletado nas profundidades de 0 a 0,10 e 0,10 a $0,20 \mathrm{~m}$, em diferentes períodos, após a aplicação da mistura comercial dos herbicidas ametryn e trifloxysulfuron-sodium

\begin{tabular}{|c|c|c|c|c|c|}
\hline \multirow{3}{*}{ Profundidade (m) } & \multicolumn{5}{|c|}{ Altura $(\mathrm{cm})$} \\
\hline & \multicolumn{5}{|c|}{ Tratamento ${ }^{\underline{1} /}$} \\
\hline & 1 & 2 & 3 & 4 & 5 \\
\hline & \multicolumn{5}{|c|}{$1^{\text {a }}$ Coleta $^{2 / l}$} \\
\hline $0-0,10$ & $7,46 \mathrm{aA}$ & $9,40 \mathrm{bA}$ & $3,92 \mathrm{aB}$ & $6,92 \mathrm{aA}$ & $8,54 \mathrm{aA}$ \\
\hline \multirow[t]{2}{*}{$0,10-0,20$} & $8,28 \mathrm{aA}$ & $6,68 \mathrm{aAB}$ & $5,22 \mathrm{aB}$ & $6,93 \mathrm{aAB}$ & $5,78 \mathrm{bAB}$ \\
\hline & \multicolumn{5}{|c|}{$2^{\text {a }}$ Coleta } \\
\hline $0-0,10$ & $16,33 \mathrm{aA}$ & $17,74 \mathrm{aA}$ & $9,67 \mathrm{aBC}$ & $8,18 \mathrm{bC}$ & $12,50 \mathrm{aB}$ \\
\hline \multirow{2}{*}{$0,10-0,20$} & $12,60 \mathrm{bA}$ & $13,01 \mathrm{bA}$ & $11,00 \mathrm{aA}$ & $11,96 \mathrm{aA}$ & $13,06 \mathrm{aA}$ \\
\hline & \multicolumn{5}{|c|}{$3^{\mathrm{a}}$ Coleta } \\
\hline $0-0,10$ & $8,69 \mathrm{aA}$ & $6,21 \mathrm{aA}$ & $7,37 \mathrm{aA}$ & $6,58 \mathrm{aA}$ & $9,37 \mathrm{aA}$ \\
\hline \multirow[t]{2}{*}{$0,10-0,20$} & $6,45 \mathrm{aA}$ & $4,82 \mathrm{aA}$ & $4,21 \mathrm{aA}$ & $5,08 \mathrm{aA}$ & $6,12 \mathrm{aA}$ \\
\hline & \multicolumn{5}{|c|}{ 4- Coleta } \\
\hline $0-0,10$ & $5,08 \mathrm{aA}$ & $6,60 \mathrm{aA}$ & $6,18 \mathrm{aA}$ & $5,71 \mathrm{aA}$ & $6,25 \mathrm{aA}$ \\
\hline $0,10-0,20$ & $4,04 \mathrm{aA}$ & $5,09 \mathrm{bA}$ & $4,67 \mathrm{bA}$ & $4,33 \mathrm{bA}$ & $5,15 \mathrm{aA}$ \\
\hline
\end{tabular}

Médias seguidas pela mesma letra minúscula (coluna) ou maiúscula (linha) não diferem entre si, pelos testes $\mathrm{F}$ e de Tukey ( $\mathrm{P}>0,05$ ), respectivamente, para cada coleta; ${ }^{1 /}$ Os tratamentos 1,2 e 3, 4 referem-se, respectivamente, às aplicações em pré e pós-emergência em 2003 e 2003/2004, além do tratamento 5 (testemunha) sem herbicida; 를 As $1^{\mathrm{a}}, 2^{2 \mathrm{a}}, 3^{\mathrm{a}} \mathrm{e} 4^{\mathrm{a}}$ coletas referem-se, respectivamente, às datas de 10/8, 10/10, 10/11/2004 e 10/2/2005 de amostragem do solo. 
de diversos herbicidas (Vieira et al., 1999; Procópio et al., 2001). Portanto, quanto menor a sua sorção, maior é seu efeito herbicida. O menor percentual de argila e, principalmente, os teores inferiores de MO do solo coletado na subárea com a var. SP 801816 contribuem para a maior disponibilidade dos herbicidas na solução do solo, sendo sua ação mais pronunciada sobre a espécie indicadora $C$. satiuus, conforme verificado no bioensaio. Embora existam inúmeros interferentes nas características de sorção de herbicidas à matéria orgânica, Cox et al. (1998) ressaltam que a interação herbicida-matéria orgânica é mais estável do que aquela resultante da ligação com componentes minerais do solo e que, nesses solos, existe, em geral, menor tendência de lixiviação de herbicidas, representando menor risco de contaminação de águas subterrâneas.

As estimativas dos resíduos de ametryn + trifloxysulfuron-sodium (apresentadas na Figura $4 \mathrm{a}$ e b) - para o solo cultivado nas

Tabela 7 - Estimativas das médias de biomassa seca (\% em relação à testemunha) das plantas indicadoras de Cucumis sativus em Argissolo Vermelho-Amarelo eutrófico cultivado com cana-de-açúcar (SP 791011), coletado nas profundidades de 0 a 0,10 e 0,10 a $0,20 \mathrm{~m}$, em diferentes períodos, após a aplicação da mistura comercial dos herbicidas ametryn e trifloxysulfuron-sodium

\begin{tabular}{|c|c|c|c|c|}
\hline \multirow{3}{*}{$\begin{array}{l}\text { Profundidade } \\
\text { (m) }\end{array}$} & \multicolumn{4}{|c|}{ Biomassa Seca (\%) } \\
\hline & \multicolumn{4}{|c|}{ Tratamento $^{\nu}$} \\
\hline & 1 & 2 & 3 & 4 \\
\hline & \multicolumn{4}{|c|}{$1^{\text {a }^{-}}$Coleta $^{\underline{\underline{y}}}$} \\
\hline $0-0,10$ & $108,19 \mathrm{bA}$ & $112,06 \mathrm{aA}$ & $55,36 \mathrm{bB}$ & $110,79 \mathrm{bA}$ \\
\hline \multirow[t]{2}{*}{$0,10-0,20$} & $157,90 \mathrm{aA}$ & $135,10 \mathrm{aA}$ & $111,61 \mathrm{aA}$ & $106,76 \mathrm{aA}$ \\
\hline & \multicolumn{4}{|c|}{$2^{\text {a }}$ Coleta } \\
\hline $0-0,10$ & $124,14 \mathrm{aA}$ & $129,29 \mathrm{aA}$ & $73,01 \mathrm{aB}$ & $71,85 \mathrm{bB}$ \\
\hline \multirow[t]{2}{*}{$0,10-0,20$} & $105,23 \mathrm{aA}$ & $106,79 \mathrm{bA}$ & $93,72 \mathrm{aA}$ & $94,49 \mathrm{aA}$ \\
\hline & \multicolumn{4}{|c|}{$3^{\text {a }}$ Coleta } \\
\hline $0-0,10$ & $117,16 \mathrm{aA}$ & $99,49 \mathrm{aA}$ & $116,90 \mathrm{aA}$ & $79,64 \mathrm{aA}$ \\
\hline \multirow[t]{2}{*}{$0,10-0,20$} & $104,97 \mathrm{aA}$ & $93,14 \mathrm{aA}$ & $89,21 \mathrm{aA}$ & $107,74 \mathrm{aA}$ \\
\hline & \multicolumn{4}{|c|}{ 4- Coleta } \\
\hline $0-0,10$ & $99,59 \mathrm{aA}$ & $96,15 \mathrm{aA}$ & $100,73 \mathrm{aA}$ & $89,40 \mathrm{aA}$ \\
\hline $0,10-0,20$ & $101,41 \mathrm{aA}$ & $94,99 \mathrm{aA}$ & $82,77 \mathrm{bA}$ & $90,80 \mathrm{aA}$ \\
\hline
\end{tabular}

Médias seguidas pela mesma letra minúscula (coluna) ou maiúscula (linha) não diferem entre si pelos testes $\mathrm{F}$ e Tukey $(\mathrm{P}>0,05)$, respectivamente, para cada coleta. ${ }^{\underline{1}}$ Os tratamentos 1,2 e 3, 4 referem-se, respectivamente, às aplicações em pré e pós-emergência em 2003 e 2003/2004. O tratamento 5 - testemunha (não apresentado) foi considerado como $100 \%$ de biomassa seca. $\stackrel{2 /}{-}$ As $1^{\mathrm{a}}, 2^{\mathrm{a}}, 3^{\mathrm{a}}$ e $4^{\mathrm{a}}$ coletas referem-se, respectivamente, às datas 10/8, 10/10, 10/11/2004 e 10/2/2005 de amostragem do solo. subáreas com as var. SP 791011 e SP 801816, respectivamente - são representativas dos percentuais de fitotoxicidade observados na Figura 3. Verifica-se que a maior parte estimada dos resíduos permaneceu na profundidade de 0 a $0,10 \mathrm{~m}$, com decréscimo dos resíduos de ametryn + trifloxysulfuron-sodium a partir da primeira para a última coleta do solo.

Para o solo com a var. SP 801816 (Figura 4-b), observa-se que somente no tratamento 3 a planta indicadora demonstrou a presença de resíduos na última coleta, não sendo constatada ação residual dos herbicidas nos
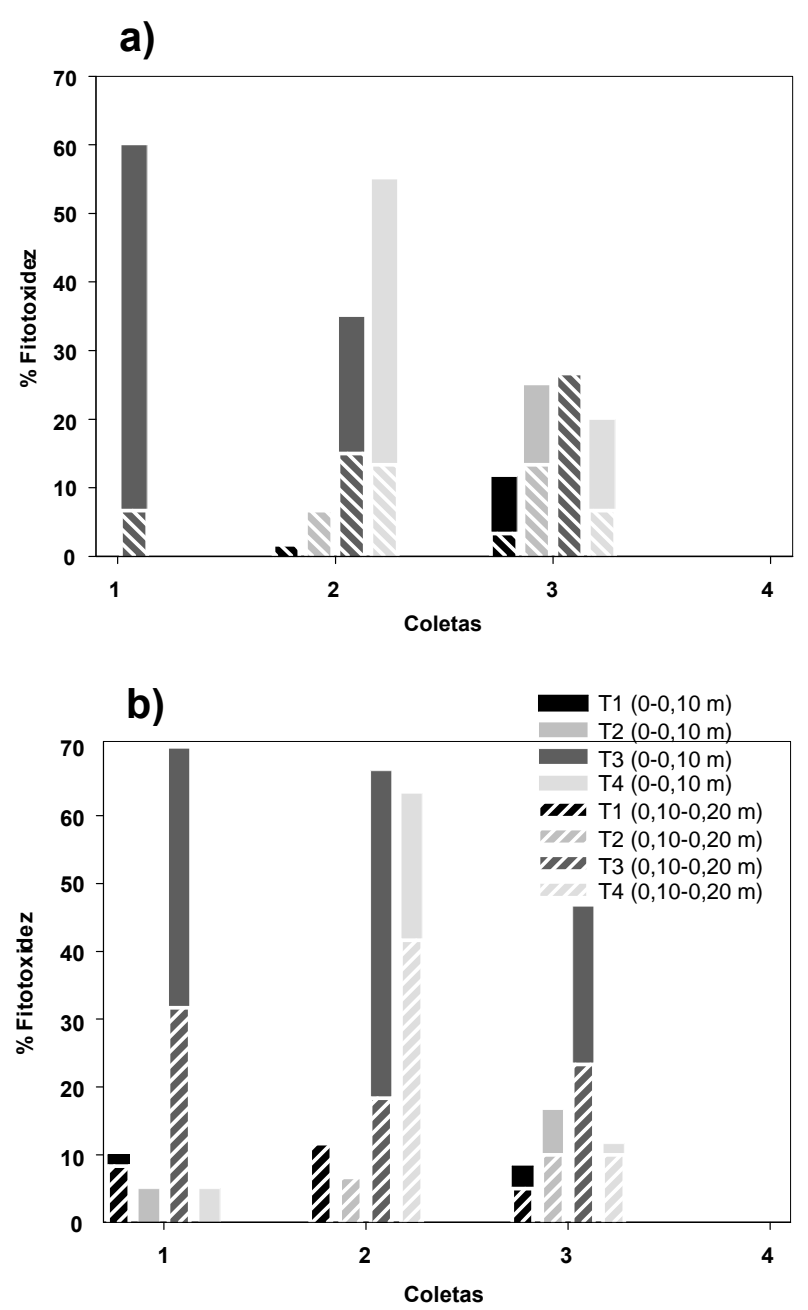

Figura 3 - Estimativas do percentual de intoxicação das plantas de Cucumis sativus, em Argissolo Vermelho-Amarelo eutrófico cultivado com cana-de-açúcar - a) SP 791011 e b) SP 801816 - coletado nas profundidades de 0 a 0,10 e 0,10 a $0,20 \mathrm{~m}$, em diferentes períodos, após a aplicação da mistura comercial dos herbicidas ametryn e trifloxysulfuronsodium. 

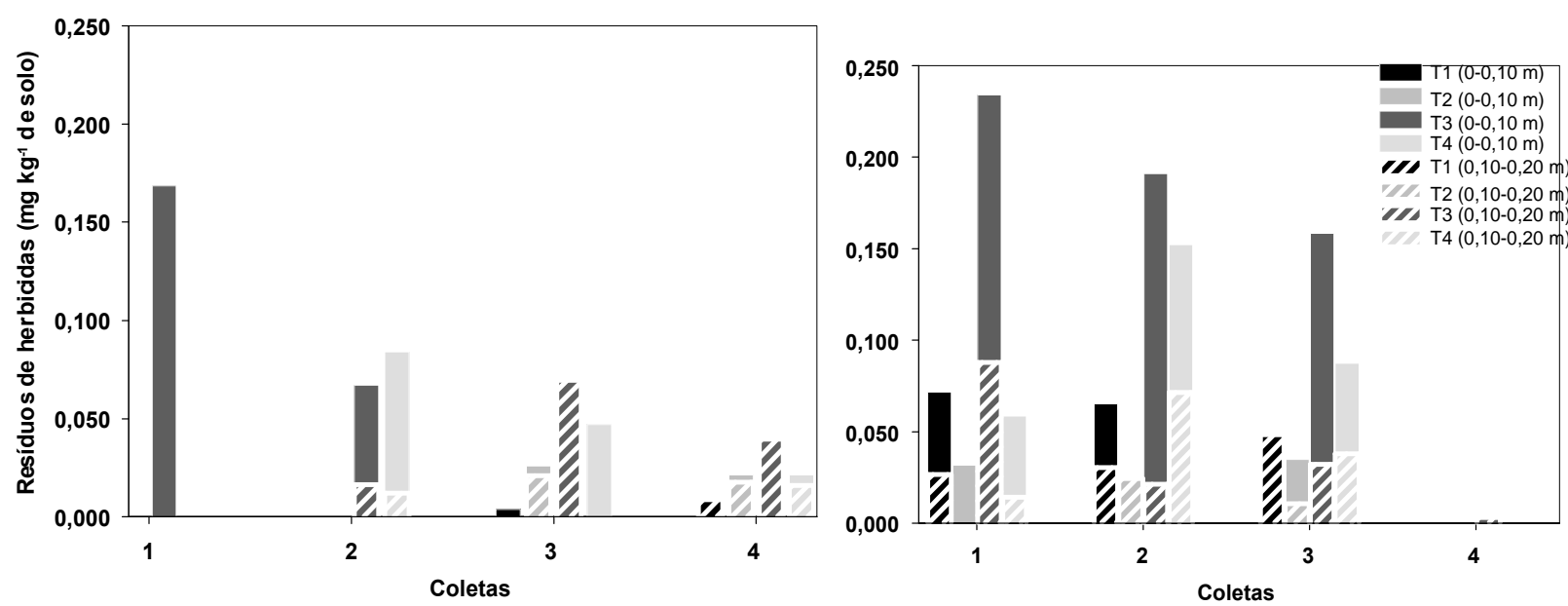

Figura 4 - Estimativas dos resíduos da mistura comercial dos herbicidas ametryn e trifloxysulfuron-sodium nas profundidades de 0 a 0,10 e 0,10 a 0,20 m, em Argissolo Vermelho-Amarelo eutrófico cultivado com cana-de-açúcar - a) SP 791011 e b) SP 801816 - em função da curva de dose-resposta da biomassa seca das plantas indicadoras de Cucumis sativus.

demais tratamentos. Entretanto, na subárea com a var. SP 791011, embora em menor quantidade, os resíduos da mistura comercial ametryn + trifloxysulfuron-sodium foram significativos até a última avaliação, com maior permanência no local. Essa constatação enfatiza a maior capacidade de sorção já observada para o solo cultivado com essa variedade, o que garante menor disponibilidade desses compostos ao ataque microbiano e lixiviação para camadas inferiores do perfil do solo (Andréa \& Luchini, 2002). Na subárea cultivada com a var. SP 791011, verifica-se também que, embora não se tenha constatado ação residual dos herbicidas nos tratamentos $1 \mathrm{e}$ 2, na primeira coleta de solo, correspondente aos 490 e 467 DAA em pré e pós-emergência, respectivamente, foram encontrados resíduos em relação a esses tratamentos na terceira e quarta coletas, sendo o período de maior precipitação na área $(>100 \mathrm{~mm}$ mensais Figura 1). A provável explicação para isso está na capacidade de dessorção de ametryn e trifloxysulfuron-sodium da fase sólida para a solução do solo, decorrente do aumento dos teores de água, o que tornaria esses herbicidas disponiveis para absorção e ação sobre a planta indicadora. Conforme Van Alphen \& Stoorvogel (2002), os processos de lixiviação e contaminação de águas por pesticidas são fortemente influenciados pela variabilidade do solo, o qual sofre a ação direta das condições climáticas locais, devendo estas ser incorporadas nos estudos de comportamento de herbicidas em campo.

Embora o método de bioensaio tenha sido satisfatório para a avaliação dos resíduos de ametryn + trifloxysulfuron-sodium no solo, principalmente pela facilidade de execução e baixo custo, verifica-se que ele não possibilita a distinção na quantificação desses herbicidas. Is so torna esse método inadequado para estimar os resíduos de misturas comerciais de herbicidas em solos, devendo-se utilizar métodos analíticos cromatográficos de separação.

Conforme proposto, a validação do método cromatográfico de análise simultânea de ametryn e trifloxysulfuron-sodium em solo atendeu aos requisitos de análise prescritos para análises em nivel de traços. As recuperações foram satisfatórias, com médias compreendidas no intervalo de 70 a $120 \%$ (Tabela 3) e precisão adequada, expressa pelos coeficientes de variação inferiores a $10 \%$. Os limites de detecção (LD) obtidos no solo PVAe foram de 0,01 e 0,02 $\mathrm{mg} \mathrm{kg}^{-1}$ para ametryn e trifloxysulfuron-sodium, respectivamente. Já os limites de quantificação (LQ), que representam os menores niveis residuais quantificados com segurança, foram de 0,04 e $0,06 \mathrm{mg} \mathrm{kg}^{-1}$ para ametryn e trifloxysulfuron-sodium, respectivamente (Tabela 3). Estes limites (LD e LQ) são semelhantes aos obtidos por 
Tavares et al. (2005) e aos descritos em outros trabalhos com análise por cromatografia liquida.

Observa-se, na Figura 5, que apenas o herbicida ametryn foi quantificado para as amostras de solo coletadas em ambas as subáreas cultivadas com as var. SP 791011 (a) e SP 801816 (b). Para o herbicida trifloxysulfuron-sodium, os resíduos permaneceram, na maioria das análises, abaixo do LQ do método, não sendo detectado nas demais. Considerando a dose aplicada de $37 \mathrm{~g}$ i.a. ha ${ }^{-1}$ e levando-se em consideração o solo na profundidade de 0 a $0,10 \mathrm{~m}$, verifica-se que a quantidade total disponivel por grama de solo já seria inferior ao LQ do método, confirmando a ausência de quantificação desse composto.

No entanto, resíduos de ametryn foram quantificados em todo o período amostral, principalmente para os tratamentos 3 e 4 , com traços residuais para o tratamento 1 , na primeira coleta (Figura 5). Em concordância com os valores obtidos por bioensaio, verifica-se que a maioria desse herbicida permaneceu na camada de 0 a $0,10 \mathrm{~m}$ de profundidade do solo, embora os valores residuais encontrados tenham sido superiores aos estimados por bioensaio. Nas avaliações realizadas para as amostras entre 0,10 e $0,20 \mathrm{~m}$ de coleta do solo, observa-se que, para ambas as subáreas de cultivo, foi possível a quantificação de ametryn nessa profundidade, enfatizando-se os riscos de lixiviação desse herbicida na contaminação de águas subterrâneas. Em estudo conduzido por Lanchote et al. (2000) em solos brasileiros, resíduos de ametryn foram encontrados na maioria das amostras de água coletadas em áreas de cultivo de cana-de-açúcar, embora te nham permanecido abaixo dos níveis residuais máximos estabelecidos pela agência internacional de controle ambiental. Em trabalhos realizados por Rand (2004) também se verificou que o ametryn, juntamente com DDD e DDE, foram os pesticidas detectados com maior freqüência em sedimentos de rios de áreas agrícolas na Flórida.

Em relação ao tempo de permanência de ametryn, verifica-se a presença de resíduos até a última data de coleta do solo, correspondente aos 198 e 165 DAA dos tratamentos 3 e 4, o que pode ser considerado como de alta persistência no ambiente. Segundo Prates et al. (2001), a baixa porcentagem de mineralização de ametryn, juntamente com o fato de este não ser metabolizado e não formar resíduo ligado, aumenta a sua permanência no solo, demandando atenção no comportamento dessa molécula em relação a prováveis problemas ambientais.

Além disso, observa-se que, ao contrário do constatado pelo método do bioensaio, os maiores teores residuais, determinados pelo método cromatográfico, se encontram no solo cultivado com a var. SP 791011 . Isso pode ser explicado pelo entendimento dos métodos utilizados. Enquanto a metodologia por
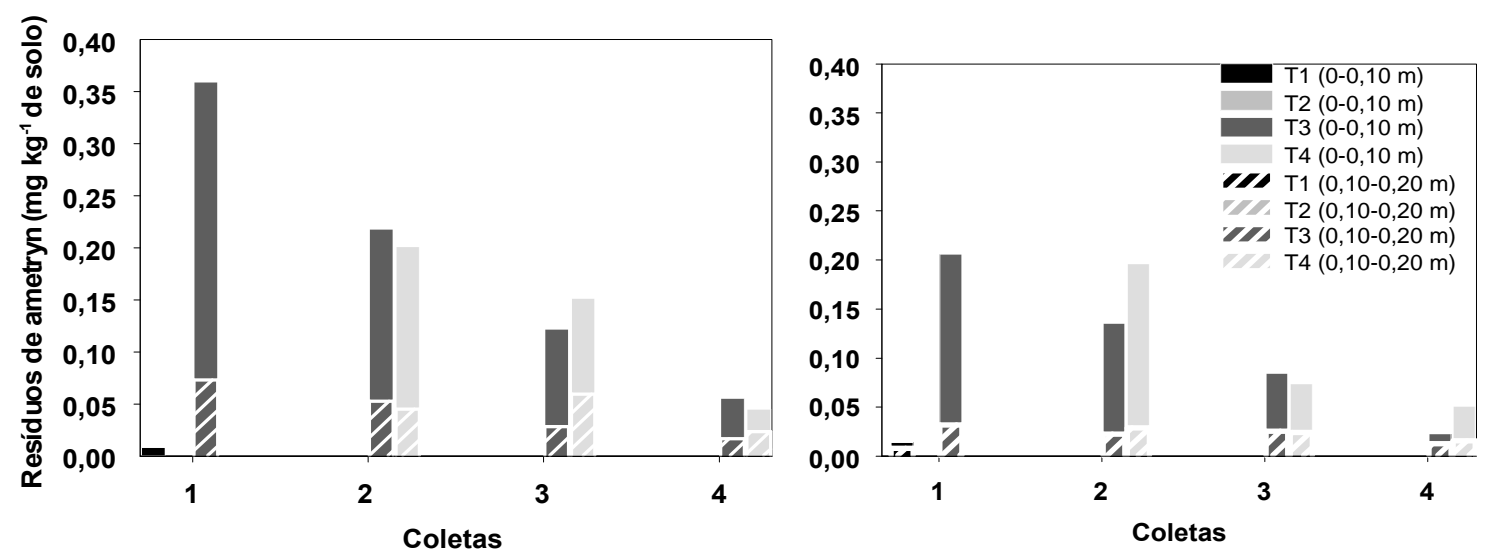

Figura 5 - Estimativas dos resíduos do herbicida ametryn determinados por cromatografia líquida, nas profundidades de 0 a 0,10 e 0,10 a 0,20 m, em Argissolo Vermelho-Amarelo eutrófico cultivado com cana-de-açúcar - a) SP 791011 e b) SP 801816). 
bioensaio permite a estimativa indireta dos resíduos dos compostos, a separação e quantificação por cromatografia avaliam a quantidade real presente na amostra. Em adição, a solução extratora consegue retirar a maioria do herbicida adsorvido no solo, de forma que, quanto maior a capacidade de ele reter o herbicida, menor será sua degradação no meio e, conseqüentemente, maior a quantidade extraída pela solução utilizada.

Embora não tenham sido constatados relatos na literatura sobre a dinâmica de trifloxysulfuron-sodium em solos, ressalta-se que, devido à sua baixa dosagem utilizada e reduzida toxicidade para mamíferos, seu uso torna-se favorável ao meio ambiente. Entretanto, sua persistência e uso repetitivo na mesma área precisam ser mais investigados, para melhor prever seu comportamento em áreas de intensa ativi@dade agrícola.

\section{AGRADECIMENTOS}

Aos professores Antonio Augusto Neves, do Laboratório de Análises Químicas de Água - LAQUA, e Antônio Jacinto Demuner e Luiz Cláudio de A. Barbosa, do Laboratório de Sintese de Agroquímicos - LASA, pertencentes ao Departamento de Química Analítica da Universidade Federal de Viçosa.

\section{LITERATURA CITADA}

AHMAD, R. et al. Sorption of ametryn and imazethapyr in twenty five soils from Pakistan and Australia. J. Environ. Sci. Health B, v. 36, n. 2, p. 143-160, 2001.

ANDREA; M. M.; LUCHINI, L. C. Comportamento de pesticidas em solos brasileiros: a experiência do Instituto Biológico/SP. B. Inf. SBCS, v. 27, n. 2, p. 22-24, 2002.

CARTER, A. D. Herbicide movement in soils: principles, pathways and processes. Weed Res., v. 40, p. 113-122, 2000.

CARVALHO, L. C. C. Cana-de-açúcar - um mundo de oportunidades. In: ATUALIDADES agrícolas. São Paulo: Agro BASF, 2004. p. 8-9.

CLAY, D. V. Herbicide residues in soil and plants and their bioassay. In: STREIBIG, J. C.; KUDSK, P. Herbicide bioassay. Boca Raton: CRC Press, 1993. p. 153-172.
COX, L. et al. Sorption of imidacloprid on soil clay mineral and organic components. Soil Sci. Soc. Am. J., v. 62, p. 911-915, 1998.

EUROPEAN WEED RESEARCH COUNCIL- EWRC. Cite of methods in weed research. Weed Res., v. 4, p. 88, 1964.

EXTENSION TOXICOLOGY NETWORK - EXTOXNET. Pesticides information profiles. Disponível em: $<\mathrm{http} / / /$ www.extoxnet.orst.edu/pips/ametryn.htm>. Acesso em: 30 jan. 2005.

HAGER, A.; NORDBY, D. Herbicide persistence and how to test for residues in soils. In: BISSONNETTE. S. Illinois agricultural pest management handbook. Illinois: University of Illinois, 2004. p. 323-326.

KUDSK, P.; STREIBIG, J. C. Herbicides - a two edged sword. Weed Res., n. 43, p. 90-102, 2003.

LAABS, V. et al. Pesticides in surface water, sediment, and rainfall of the northeastern Pantanal basin, Brazil. J.

Environ. Qual., v. 31, p. 1636-1648, 2002.

LANCHOTE, V. L. et al. HPLC screening and CG-MS confirmation of triazine herbicides residues in drinking water from sugar cane area in Brazil. Water Air Soil Poll., v. 118, p. 329-337, 2000.

LAVORENTI, A. Comportamento dos herbicidas no solo. In: ENCONTRO BRASILEIRO DE SUBSTÂNCIAS HÚMICAS, 3., 1999. Santa Maria. Anais... Santa Maria: 1999. p. 21-34.

LIU, Z.; CLAY, S. A.; CLAY, D. E. Spatial variability of atrazine and alachlor efficacy and mineralization in an eastern South Dakota field. Weed Sci., v. 50, p. 662-671, 2002.

MITCHELL, C. et al. Sediments, nutrients and pesticide residues in event flow conditions in streams of the Mackay Whitsunday region, Australia. Marine Poll. B., v. 51, p. 23-36, 2005.

PEREIRA, H. V. Otimização e validação da extração simultânea de piretróides em água e solo e análise por cromatografia gasosa. 2005. 65 f. Dissertação (Mestrado em Agroquímica) - Universidade Federal de Viçosa, Viçosa, MG, 2005.

PFEUFFER, R. J.; RAND, G. M. South Florida ambient pesticide monitoring program. Ecotoxicology, v. 13, n. 3, p. 195-205, 2004.

PRATES, H. T. et al. Degradação e sorção de ametrina em dois solos com aplicação de vinhaça. Pesq. Agropec. Bras., v. 36, n. 7, p. 975-981, 2001.

PROCÓPIO, S. O. et al. Sorção do herbicida atrazine em constituintes organominerais. Planta Daninha, v. 19 n. 3, p. 391-400, 2001.

Planta Daninha, Viçosa-MG, v. 25, n. 1, p. 111-124, 2007 
RAND, G. M. et al. Sediment toxicity in the St. Lucie River watershed and everglades agricultural area. Ecotoxicology, v. 13, n. 3, p.261-274, 2004

RODRIGUES, B. N.; ALMEIDA, F. S. Guia de herbicidas Londrina: Instituto Agronômico do Paraná, 2005. 592 p.

SEEFELDT, S. S.; JENSEN, S. E.; FUERST, E. P. Loglogistic analysis of herbicide dose-response relationship. Weed Technol., v. 9, p. 218-227, 1995.

SILVA, A. A.; FERREIRA, F. A.; FERREIRA, L. R. Manejo de plantas daninhas. Viçosa, MG: DFT/UFV - 2005,

ABEAS, Curso por tutoria à distância, 2005. 203 p.

SKINNER, J. A. et al. An overview of the environmental impact of agriculture in the U.K. J. Environ. Manag, v. 50, p. 111-128, 1997.

SOUTHWICK, L. M. et al. Potential influence of sugarcane cultivation on estuarine water quality of Louisiana's gulf coast. J. Agric. Food Chem., v. 50, p. 4393-4399, 2002.

STORK, P.; HANNAH, M. C. A bioassay method for formulation testing and residue studies of sulfonylureia and sulfonanylide herbicides. Weed Res., v. 36, p. 271-281, 1995.
TANABE, A. et al. Seasonal and special studies on pesticides residues in surface eaters of the Shinano river in Japan.

J. Agric. Food Chem., v. 49, p. 3847-3852, 2001.

TAVARES et al. Determination of ametryn in soils via microwave-assisted solvent extraction coupled to anodic stripping voltammetry with a gold ultramicroelectrode. Anal. Bioanal. Chem., v. 382, p. 477-484, 2005.

van ALPHEN, B. J.; STOORVOGEL, J. J. Effects of soils variability and weather conditions on pesticides leaching - a farm-level evaluation. J. Environ. Qual., v. 31, p. 797-805, 2002.

VEGA, D.; CAMBON, J. P.; BASTIDE, J. Triflusulfuronmethil dissipation in water and soil. J. Agric. Food. Chem., v. 48 , p. $3733-3737,2000$.

VIEIRA, E. M. et al. Estudo da sorção/dessorção do ácido 2,4 diclorofenoxiacético (2,4-D) em solo na ausência e presença de matéria orgânica. Química Nova, v. 22, n. 3, p. 305-308, 1999.

WALKER. A. Evaluation of a simulation model for prediction of herbicide movement and persistence in soil. Weed Res., v. 27, p. 143-152, 1987. 